\title{
Are altruistic leaders worthy? The role of organizational learning capability
}

\author{
Fermín Mallén* \\ fmallen@emp.uji.es \\ Dept. of Business Administration and Marketing \\ Adjunct Lecturer \\ Universitat Jaume I \\ Ricardo Chiva \\ rchiva@emp.uji.es \\ Dept. of Business Administration and Marketing \\ Professor \\ Universitat Jaume I \\ Joaquín Alegre \\ joaquin.alegre@uv.es \\ Dept. of Business Management "Juan José Renau Piqueras" \\ Professor \\ Universidad de Valencia \\ Jacob Guinot \\ guinotj@emp.uji.es \\ Dept. of Business Administration and Marketing \\ Research Fellow \\ Universitat Jaume I
}

Acknowledgments: The authors thank the University Jaume I (Ref. P11B2008-13) and the Spanish Innovation Ministry (Ref. ECO2011-26780) for its financial support for this research.

*Corresponding author. Fermín Mallén, Universitat Jaume I, Dpto. de Administración de Empresas y Marketing, Avda. Vicent Sos Baynat, s/n, 12006 Castellón (España). e-mail: fmallen@emp.uji.es, Tel: ++34 964 728534, ++34 964 728586, Fax: ++34 963728629 


\begin{abstract}
Purpose - The purpose of this study was to investigate the relationship between altruistic leader behaviors, organizational learning capability and organizational performance.

Design/methodology/approach - The sampling frame consists of several databases or listings of business that consider people as a key element of the organization and are considered by their employees to be good firms to work for or organizational environments where human resources management has high priority $(n=251)$. We use structural equation modeling to test if the relationship between altruistic leader behaviors and organizational performance is mediated by organizational learning capability.
\end{abstract}

Findings - Results suggest that organizational learning capability fully mediates between altruistic leader behaviors and organizational performance. Thus, organizational learning capability plays a key role in explaining how altruistic leader behaviors affect organizational performance, essentially because it facilitates the creation of a creative, participatory and dialogue-based environment that promotes organizational learning.

Research limitations/implications - The database used in the study is very heterogeneous. Future research might delimit the database by organization size or sector. Qualitative studies may also improve our understanding of the relationships studied and enable other concepts to be included.

Practical implications - This study provides evidence of the positive relationship between altruistic leaders and performance. However, recruiting and fomenting altruistic leaders is not sufficient on its own to improve performance, and should be accompanied by implementing other facilitating factors of organizational learning such as dialogue or experimentation.

Originality/value - In recent years some studies have linked leadership with organizational learning. However, this is one of the first studies to concentrate on altruistic leader behaviors as such, a concept that has received scant mention in the literature despite its importance in a number of leadership styles, and its relevance today as an alternative to the egotistic leader. We offer empirical evidence of the role of altruistic leader behavior as an antecedent of organizational learning capability and subjective measures of performance.

Keywords: organizational learning capability, leadership, altruistic leader behaviors, altruism, organizational performance. 


\section{Introduction}

At the end of the last century, most extant leadership theories assumed a hedonistic leader, rather than an altruistic one (House and Aditya, 1997). The concept of altruism was rarely associated with the organizational world, mainly due to the competitive environment in which firms tend to operate, and the capitalist, individualist and Protestant roots on which they were based (Kanungo and Conger, 1993).

According to Sendjaya et al. (2008), contemporary organizations are plagued by systemic problems such as harassment by bosses, abuse of power, unethical practices, toxic emotions or social isolation and alienation in the workplace. In this context, several leadership theories based on human values are gaining ground, such as authentic leadership (Avolio and Gardner, 2005), servant leadership (Greenleaf, 1977) or spiritual leadership (Fry, 2003), and all of them share a common characteristic or dimension: altruism (Brown and Treviño, 2006). According to Smith et al. (1983) organizational altruism is a pro-social action towards members of the organization, such as helping others when they have a heavy workload, guiding people who may be confused, or helping those who have been absent. Despite its importance, very few studies have thoroughly explored this dimension, its antecedents and consequences, in the context of leadership (e.g., Sosik et al., 2009).

Dinh et al. (2014, p. 42) posit that most extant theories, even transformational leadership, failed to (sufficiently) investigate altruistic leader behaviors. There is little empirical research linking altruistic behavior and performance in the context of leadership. It may therefore be believed that altruistic leader behaviors do not correlate positively with good organizational outcomes or organizational performance. Moreover, extensive research on leadership behavior during the past half century has yielded many different behavior taxonomies and a lack of clear results about effective behaviors. The research on effects of broadly defined leader behaviors has limitations that make the results difficult to interpret 
(Yukl, 2012). In addition, other studies have moved away from the concept of the selfinterested leader, centering on specific variables that are also present in different leadership styles, such as the work of Owens and Hekman (2012) who explore the concept of humility in leaders. Thus, in our research, we concentrate on a specific behavior category of leaders (altruistic leader behaviors), rather than a leadership approach, and empirically test its relationship with organizational performance.

Leadership in organizations does not take place in a vacuum; it takes place in organizational contexts (Porter and McLaughlin, 2006, p. 559). Avolio (2007) suggested that context should be considered in all theories of leadership, because it can affect and be affected by leadership effectiveness. Therefore, the leader's behavior affects the organizational context in which he or she operates or works, and various aspects of an organization's context (for example, how centralized or formalized it is, its culture and norms, etc.) influence organizational performance. Altruistic behaviors favor contexts that are participative, cooperative and open to learning (e.g., Yen and Niehoff, 2004), which probably enhance organizational performance (e.g., Goh et al., 2012). Our view is, therefore, that leaders who behave altruistically encourage behaviors around them such as trust, support and autonomy, among others, that are involved in organizational learning capability, a construct that has been shown in previous studies to facilitate innovation, and in turn, performance (e.g., Alegre and Chiva, 2013).

Kanungo and Conger (1993) consider that the high complexity of today's economy and society call for a greater degree of interdependence (rather than independence), more attention based on cooperation (rather than competition) and greater organizational loyalty, moving away from individualism. To achieve this, altruistic acts are required from people (and leaders) in organizations and from organizations themselves, all of which seems a difficult goal in traditional bureaucratic or hierarchical organizational contexts. We therefore 
understand that the relationship between altruistic leader behaviors and organizational performance may be explained by dynamic organizational contexts that are open and disposed to learning, in other words, contexts that foster organizational learning capability.

Organizational learning capability (Chiva et al., 2007) is defined as the organizational and managerial characteristics or factors that facilitate the process of organizational learning, or that allow an organization to learn. Organizational learning scholars often focus on different forms of learning without explaining who initiates such processes (e.g., Gibson and Birkinshaw, 2004).

Thus, in this paper we analyze the mediating role of learning capability between altruistic leader behaviors and organizational performance. To this end, we conducted an empirical study of the Spanish firms most valued by their employees. We obtained a sampling frame of 402 firms, generated by combining databases or listings of businesses that regard people as a key element of the organization, and are considered by employees as good firms to work for or organizational environments where human resource management is prioritized.

Below, we briefly discuss the literature related to altruistic leader behaviors and organizational learning capability. Then, we offer a theoretical review of the relationships between the constructs that make up this study. The explanation of the methodology is followed by a discussion of the results and their theoretical and practical implications, the study's limitations and proposals for future research.

\section{Literature review and hypothesis}

\subsection{Altruistic leader behaviors}

House et al. (1999, p. 184) define leadership as the ability of an individual to influence others, motivate them and facilitate their contribution to the effectiveness and success of the 
organization. In this study we consider leadership to be the non-coercive action of motivating people to act in a certain way (Popper and Lipshitz, 1993).

According to Simmons (1991) altruism: (1) is the willingness to do things that seek to increase the welfare of others, not one's own, (2) is voluntary, (3) is intentional, involving helping others, and (4) expects no reward. Altruism is therefore the feeling or tendency to do good to others, even at the expense of personal gain.

The concept of altruistic leader behaviors differs from OCB, servant, authentic and spiritual leadership and deserves clarification:

Organ (1988) classified OCB into five distinct forms, namely, altruism, courtesy, sportsmanship, conscientiousness, and civic virtue. Altruism is therefore a kind of civic behavior, although behaving in a civic manner does not necessarily imply altruism. Sometimes, underlying motives for organizational citizenship behaviors are not altruistic at all, including the expectation of quid pro quo, promotions, pay raises, etc., as illustrated in previous research (e.g., Bolino et al., 2004).

On the other hand, altruistic behavior is implicit in some conceptualizations of leadership styles, such as spiritual, authentic and service leadership, but it is not a style in itself. Leadership styles are multidimensional constructs, broader than altruistic behavior, that include other possible behaviors. Thus, the fact that a leader displays altruistic behaviors does not necessarily imply that he or she falls within any of these leadership style theories, but rather it depends on a broader set of behaviors.

\subsection{Organizational learning capability}

Organizational learning and its facilitating factors have been shown to have a beneficial effect on organizational performance (e.g., Prieto and Revilla, 2006). Organizational learning capability is defined as the organizational and managerial characteristics or factors that facilitate the organizational learning process or allow an organization to learn (Chiva et al., 2007; Chiva and Alegre, 2009). 
Recently, Chiva et al. (2007) proposed an integrative conceptualization of organizational learning capability. As a result, Chiva et al. (2007) identified five facilitating factors of organizational learning, namely: experimentation, risk acceptance, interaction with the environment, dialogue, and participation in decision making.

Experimentation is defined as the degree to which new ideas and suggestions are attended to and dealt with sympathetically (Chiva et al., 2007). Nevis et al. (1995) consider that experimentation involves trying out new ideas, being curious about how things work, or carrying out changes in work processes. Risk taking is understood as the tolerance of ambiguity, uncertainty, and errors. Accepting or taking risks involves the possibility of mistakes and failures occurring. Interaction with the external environment is defined as the scopes of relationships with the external environment. The external environment of an organization is defined as factors that are beyond the organization's direct control of influence among others. Dialogue is defined as a sustained collective inquiry into the processes, assumptions and certainties that make up everyday experience (Isaacs, 1993:25). Finally, participative decision making refers to the level of influence employees have in the decision-making process (Cotton et al., 1988).

\subsection{Altruistic leader behaviors and organizational performance: the mediation of organizational learning capability.}

According to Zhu et al. (2005, p. 40) leadership is one of the drivers or catalysts of improved organizational performance. These authors argue that leaders, as key decision makers, determine the acquisition, development and deployment of organizational resources, and the conversion of these resources into valuable products and services. Thus, leadership is seen as a source of managerial rents and, therefore, of sustainable competitive advantage (Rowe, 2001). 
The recent trend of integrating altruism in leadership research reflects the new business environment that emphasizes ethics, teamwork, and collaboration through a more transparent decision-making process. Such forms of influence have been linked to a variety of positive outcomes, such as follower's satisfaction and high performance (Gardner et al., 2005).

Leader values and integrity did not get much attention in the early research on effective leadership, but interest in them has increased in recent years (Brown and Treviño, 2006). Values such as honesty, altruism, compassion, fairness, courage, and humility are emphasized in servant leadership theory (Greenleaf, 1977) and spiritual leadership theory (Avolio and Gardner, 2005). Proponents of these theories contend that leaders whose behavior reflects these values will be more effective (Yukl, 2012).

There is a growing body of empirical evidence that indicates a positive relationship between altruistic behavior and managerial performance ratings (e.g., Organ et al., 2006). Such behavior of organizational members has also been linked to both perceived and objective measures of organizational performance (Cameron et al., 2004). Podsakoff and MacKenzie (1997) demonstrated that each of the dimensions of OCB positively impacts organizational performance; altruistic behavior was found to be the strongest, most reliable predictor of various indices of organizational success, such as the stability of organizational performance. Given the nature of $\mathrm{OCB}$, it has often been classified into five distinct forms, namely, altruism, courtesy, sportsmanship, conscientiousness, and civic virtue (Organ, 1988). Of these five forms, altruism is the most frequently studied because it has direct implications for the bottom line of business, and is a strong predictor of organizational performance (Batson et al., 2011).

Hence, the literature seems to suggest that altruistic leader behaviors within organizations favor organizational performance.

However, although leadership has an impact on organizational performance, many studies have considered and analyzed how certain variables or constructs mediate this 
relationship, such as certain human resource management policies (Zhu et al., 2005), the organizational culture (Xenikou and Simosi, 2006), or organizational commitment (Steyrer et al., 2008). Ozcelik et al. (2008) find a positive relationship between certain leadership practices that foster a positive emotional climate and organizational performance. Similarly, but from an organizational learning perspective, Garcia-Morales, et al. (2008) demonstrate empirically that the organizational learning variable mediates the relationship between transformational leadership and organizational performance. Thus organizational learning can be considered as a mediating variable between leadership and performance.

Kanungo and Mendonca (1996) propose that leaders motivated by altruism are much more effective than those who act for egotistical reasons. Leaders who show a selfless concern for the welfare of others, or who seek the good of others even to their own detriment, are likely to generate an environment of cooperation and trust in which it is easier to learn, experiment, participate, discuss or take risks, all of which result in better performance, since these factors are, according to Chiva et al. (2007), the facilitating factors of organizational learning, and have previously been related to organizational performance (Alegre and Chiva, 2013).

Leadership style is one of the aspects mentioned in the organizational learning literature, which suggests it is essential for the development of organizational learning or organizational learning capability (Berson et al., 2006). The literature points to various leadership styles such as transformational, servant, spiritual or authentic leadership (Berson et al., 2006; Fry et al., 2005; Gardner et al., 2005; Lloréns-Montes et al., 2005) as some of the antecedents of organizational learning. Authentic, transformational, servant and spiritual leaders are motivated by altruism (rather than by self-interest), demonstrating a genuine caring and concern for others (Brown and Treviño, 2006). One of the essential characteristics of such leaders is therefore altruism. In addition, the literature has also shown that organizational citizenship behavior, which includes altruism, has a positive influence on 
organizational learning (Chang et al., 2011). Hence, the literature seems to suggest that altruistic behavior within organizations favors organizational learning. Altruism displayed by managers might therefore be understood as an antecedent of organizational learning capability.

We can therefore claim that altruistic leader behaviors can improve organizational learning capability, which, in turn can enhance organizational performance. The above leads to the following hypothesis:

Hypothesis 1: The relationship between altruistic leader behaviors and organizational performance is mediated by organizational learning capability.

\subsection{Altruistic leader behaviors and organizational learning capability}

To our knowledge, there are no studies relating the concept of altruistic leader behaviors as such with organizational learning capability and organizational learning. However, many studies have associated leadership or various styles of leadership with organizational learning. Vera and Crossan (2004) argue that transactional leadership promotes adaptive learning, whereas transformational leadership encourages generative learning. Adaptive learning is reacting almost automatically to stimuli to make changes in process and outcome as a coping mechanism, whereas generative learning is learning proactively and intentionally, and applying new skills, knowledge, behaviors and interaction patterns to improve the team's performance (Valerie et al., 2011). García-Morales et al. (2008) empirically demonstrate that transformational leadership facilitates the development of organizational learning. Fry (2003) believe that spiritual leadership is essential to achieve a learning organization. Berson et al. (2006) understand that leadership affects the context or

culture that promotes organizational learning, which is similar to organizational learning capability. It therefore seems clear that new styles of leadership, in general, can be considered to have a direct and positive effect on organizational learning capability. 
While authoritarian forms of leadership may actually inhibit learning (Berson et al., 2006), leadership styles where altruistic leader behavior is a relevant characteristic, encourage learning of individuals and teams by loosening leader control and creating a safe and supportive environment where people feel that they can take risks, make mistakes, create dialogue and be supported in a manner that is necessary for learning to occur (Fry et al., 2005).

Perceptions of support allow followers to feel more autonomy and a level of freedom to challenge the status quo and pursue projects with risks and unknown outcomes (Tierney et al., 1999). This autonomy relates to the concept of empowerment, which according to Kanungo and Conger (1993) contains elements of altruistic behavior. A leader who empowers the members of their organization: (1) involves members in making important related decisions and considers their suggestions and concerns; (2) delegates responsibility and authority to members for important tasks and allows them to resolve work-related problems without prior approval (Yukl, 2012). Hence, this climate of support might promote taking risks and a certain degree of participative decision making.

Members of groups which are in a position to initiate learning behavior, such as seeking feedback, sharing information, asking for help, talking about errors, and experimenting needs may be reluctant to such behaviors, unless they feel secure (Edmonson, 1999). By creating a climate of psychological safety, leaders can increase learning from mistakes and failures and encourage members of the organization to suggest novel ideas (Yukl, 2012). The psychological safety category also incorporates freedom to take risks, trust, and support (Berson et al., 2006). Therefore, supportive and safe environments created by organizational leaders can lead to the promotion of psychological safety and, therefore, enhance dialogue, propensity to take risks and members experimentation.

Organizational members are particularly aware of the behavior of the leader (Tyler and Lind, 1992). Given a manager's sphere of influence and potential as a role model for 
subordinates, managers who display altruistic leader behaviors may encourage such behavior among subordinates and build prosocial cultures of helping and citizenship (Sosik et al., 2009). A worker behaves altruistically when he or she helps or cooperates with another worker voluntarily on a task (Fassina et al., 2008). Accordingly, altruistic behavior within organizations may encourage interaction between parties. Since altruistic behaviors seek to assist or cooperate with others, they also offer the possibility for contact and interaction with others, thereby favoring information exchange and communication. Indeed, the literature suggests that altruism is positively related to cooperation (Yen and Niehoff, 2004), information exchange (Daily and Dollinger, 1992) and communication (Gersick et al., 1997). Consequently, it seems logical to suggest that altruism within organizations increases the likelihood of interaction with others, which could contribute positively to dialogue and communication, and also open up possibilities for interaction with the external environment.

Altruistic leader behaviors therefore appear to be closely linked to the dimensions or factors that facilitate organizational learning. Altruistic leader behaviors seem to favor an organizational climate, where risk taking, participatory decision making, experimentation, interaction with the environment, and communication are promoted. As a result, we suggest in this study that altruistic leader behaviors could improve organizational learning capability.

Therefore, we propose the following hypothesis:

Hypothesis 2: Altruistic leader behavior is positively related to organizational learning capability

\subsection{Organizational learning capability and organizational performance}

Jerez-Gomez et al. (2005) find a positive relationship between organizational learning capability and organizational performance. Recently, Garcia-Morales et al. (2011) point to the positive effect of learning on innovation and organizational performance. Similarly, Alegre and Chiva (2013) show that organizational learning capability affects organizational performance through innovation. 
Many other studies have examined the relationship between organizational learning capability and organizational performance. Some studies confirm the proposed relationship based on analysis of firms in different countries, such as India (Khandekar and Sharma, 2006), or Spain (Prieto and Revilla, 2006). Other studies explore this relationship among small businesses (Spicer and Sadler-Smith, 2006). In all these cases, a positive relationship is found between organizational learning capability and different measures of performance. Recently, Goh et al. (2012) drew the same conclusion following a meta-analysis of the relationship between organizational performance and organizational learning capability.

We can therefore hypothesize that:

Hypothesis 3: There is a positive relationship between organizational learning capability and organizational performance.

\section{INSERT FIGURE 1 ABOUT HERE}

\section{Research methodology}

\subsection{Data collection}

To test the hypotheses, we designed a questionnaire addressed to the Spanish companies most highly valued by their employees. The sampling frame, totaling 402 companies, consists of several databases or listings of businesses that consider people as a key element of the organization and are considered by their employees to be good firms to work for or organizational environments where human resources management has high priority. We consulted company listings that meet these characteristics (the CRF Institute's 'Top Companies to Work For' and 'Top Employers', firms from the Great Place to Work consulting company list, the Merco Personas list of best companies to work for, published by the journal Actualidad Económica in August 2010). We consider that because of the qualities these firms possess, many other firms use them as benchmarks in their own improvement 
processes. As a result, we believe that the relationships among the variables arising in these working environments is a subject worthy of in-depth examination.

The fieldwork was carried out between October and December of 2010; the questionnaire (in Spanish) was addressed to managers with at least two years' experience in the firm, preferably human resources managers.

The questionnaire consisted of 23 items and was completed via telephone interviews, giving a total of 251 valid questionnaires. The sample therefore represents $62.44 \%$ of our sampling frame, which is highly satisfactory.

\subsection{Measurement instruments}

3.2.1. Altruistic leader behavior. Barbuto and Wheeler (2006) developed a questionnaire to measure servant leadership, and it includes five subscales: altruism, organizational stewardship, persuasive mapping, wisdom and emotional healing. The subscale for altruism involves behaviors that reflect altruistic values (appendix A).

3.2.2. Organizational learning capability. The scale developed by Chiva et al. (2007) and Chiva and Alegre (2009) was used to measure organizational learning capability. This scale consists of five dimensions (experimentation, risk acceptance, interaction with the environment, dialogue, and participation in decision making) and a total of 14 items, as shown in Appendix A.

3.2.3. Organizational performance. We used subjective measures of performance evaluation, due to the difficulties involved in obtaining an objective measure of this construct, and the problems associated with using accounting variables (Christmann, 2000). Various studies find a positive relationship between subjective and objective measures of organizational performance (e.g., Gatignon et al., 2002). We used the scale proposed by 
Tippins and Sohi (2003), as shown in appendix A. A 5-point Likert-type scale was also used, where 1 denotes the lowest score for a firm relative to its competitors, and 5 the highest.

\subsection{Control variable}

We used firm size and sector as control variables. Participants in our study were asked to classify their firms into one of six categories according to the number of employees (frequencies for each category in our sample appear in brackets): fewer than 50 employees (13.9\%), 50-100 employees (21.5\%), 101-250 employees (25.9\%), 251-500 employees (23.9\%), 501-1,000 employees (10.4\%), and firms with more than 1,000 employees (4.4\%). With regard to sector, $28.7 \%$ of the organizations belonged to manufacturing sectors, while $71.3 \%$ were from service sectors.

\subsection{Analysis}

The empirical validation of the model was performed using structural equations and the EQS 6.1 statistical software. We used the maximum likelihood (ML) estimation method with robust estimators.

Given that the scales were developed using relevant items selected from a common survey, we conducted a Harman's single factor test (Podsakoff and Organ, 1986) to control for common method variance and to deal with the potential social desirability of the responses. The results of the CFA with the 23 indicators loading onto a single factor (Satorra-Bentler chi-square $=1538.53 ; \mathrm{p}$-value $=0.00 ; \mathrm{BBNFI}=0.336 ; \mathrm{CFI}=0.366$; RMSEA $=0.151 ;$ SB chi-square/d.f. $=6.69)$ showed a poor fit, suggesting that the singlefactor does not account for all the variance in the data.

\section{Results}

\subsection{Descriptive statistics and psychometric properties of the measurement scales}

The data analysis begins with the descriptive statistics. Table 1 exhibits means, standard deviations and factor correlations. The psychometric properties of the measurement 
scales were evaluated following accepted practices in the literature (Anderson and Gerbing, 1988), namely, analyses of dimensionality, reliability, and content, convergent and discriminant validity (Tippins and Sohi, 2003).

\section{INSERT TABLE 1 ABOUT HERE}

In the case of organizational learning capability a second-order confirmatory factor analysis was conducted to verify the scale's multidimensionality (Figure 2). Likewise, the structure or dimensionality of the variables was tested as a whole using a full measurement model in which all the constructs were included (Anderson \& Gerbing, 1988). The overall fit of this general measurement model was as follows: chi-square (d.f.) $=224.29(201) ; p=0.12$; $\mathrm{CFI}=0.988 ; \mathrm{RMSEA}=0.022$. Therefore, the results obtained in the full measurement model suggest that the three constructs used in this study were indeed separate and distinct.

\section{INSERT FIGURE 2 ABOUT HERE}

The results of the reliability analyses are also satisfactory (Table 2). Cronbach's alpha coefficient and composite reliability values were above 0.8 , exceeding the minimum accepted value of 0.7 (Nunnally, 1978).

INSERT TABLE 2 ABOUT HERE

Content validity is supported by the procedure used to select the measurement scales. The altruistic leader behavior dimension items were taken from a scale validated in a 
previous study (Barbuto and Wheeler, 2006), in which the altruistic leader behavior dimension was introduced as one component of servant leadership. The variables used to measure organizational performance were also proposed and used in a previous study in 2003 by Tippins and Sohi. Finally, organizational learning capability was measured using the scale developed by Chiva et al. (2007) and Chiva and Alegre (2009), which was based on a thorough literature review and later validated.

We used procedures accepted in the literature to study the convergent and discriminant validity. Following Fornell and Larcker (1981), if the average variance extracted for a factor is below 0.50 , its convergent validity is questionable. The average variance extracted for the three constructs in this study are clearly above the limit of 0.50 , confirming the existence of convergent validity. We applied two methods to assess whether the requirement of discriminant validity is also satisfied. First, we analyze whether the average variance extracted of each construct is greater than the squared correlation coefficients between constructs (Fornell and Larcker, 1981). All the correlations are significant and below 0.9. In addition, the average variance extracted for each dimension is clearly above the squared correlation of a construct with any of the others comprising the measurement scale. We also conducted a second, more stringent test of discriminant validity, which determines whether the correlations between factors are significantly different from +1 or -1 (Bagozzi et al., 1991). The resulting $95 \%$ confident intervals are computed as parameter estimate $\pm 1.96 *($ std. error) and unity was not present in any of the intervals (showing discriminant validity).

In sum, we conclude that all the scales meet convergent and discriminant validity requirements.

\subsection{Verification of the research hypotheses}

We followed the approach taken by Tippins and Sohi (2003), to verify the existence of the mediating effect of organizational learning capability on the relationship between altruistic leader behaviors and organizational performance (hypothesis 1). This approach 
entails developing two models, a direct effect model and a mediator model, and conducting a sequential analysis of them. In addition, in order to evaluate the significance of the mediated effect we use bootstrapping, which is an additional method advocated for testing mediation that does not impose the assumption of normality of the sampling distribution (Preacher and Hayes, 2008). MacKinnon et al. (2012) suggest the use of bootstrapping methods for determining the significance of the mediated effect along with a confidence interval for the indirect effect.

We first analyze the results of the model posing a direct relationship between altruistic leader behaviors and organizational performance (Figure 3). Except for the control variable size, all the standardized parameters are statistically significant $(\mathrm{t} \geq 1.96$, for a 0.05 significance level). Results indicate the excellent fit of the direct effect model: chi-square $($ d.f. $)=49.54(34) ; \mathrm{p}=0.04 ; \mathrm{NFI}=0.943 ; \mathrm{NNFI}=0.975 ; \mathrm{CFI}=0.981 ; \mathrm{RMSEA}=0.043$ Finally, the normed chi-square presents a value of 1.46, within the most demanding range of 1 and 2.

INSERT FIGURE 3 ABOUT HERE

Before interpreting the parameters used to test our hypotheses, we evaluate the fit of the mediating effect model (Figure 4). As in the previous case, again with the exception of the control variable, the estimated parameters are all statistically significant, with t values clearly above the 1.96 limit. From the review of absolute, incremental and parsimonious fit measures we can conclude that the fit of this model is also excellent (Satorra-Bentler chi-square (d.f.)= $280.60(244) ; \mathrm{p}$-value $=0.054 ; \mathrm{NFI}=0.882 ; \mathrm{NNFI}=0.980 ; \mathrm{CFI}=0.983 ; \mathrm{RMSEA}=0.024)$ Table 3 presents the structural equations resulting from our analysis. 


\section{INSERT TABLE 3 ABOUT HERE}

Tippins and Sohi (2003) refer to four conditions that must be met for mediation to be supported:

(1) The partial mediation model explains more variance in organizational performance than the direct effect model (0.209 vs. 0.073). Table 3 represents the structural equations of our hypotheses.

(2) In the mediation model, there must be a significant relationship between altruistic leader behavior and organizational learning capability $\left(\beta_{2}=0.556, \mathrm{t}=4.709, \mathrm{p}<\right.$ $0.01)$.

(3) The significant relationship between altruistic leader behavior and organizational performance, observed in the direct effect model, must decrease considerably or disappear in the partial mediation model. The results reported in table 3 indicate a moderate, direct and significant relationship between altruistic leader behavior and organizational performance $(\alpha=0.215, \mathrm{t}=3.079, \mathrm{p}<0.01)$. This result confirms that altruistic leader behavior significantly affects firm performance, and also that organizational performance depends on a number of factors (Capon et al., 1990), one of which is altruistic leader behavior. When this relationship is analyzed, including the mediation of organizational learning capability, the direct effect is close to zero and not significant $\left(\beta_{1}=-0.027, \mathrm{t}=-0.318\right)$, while the indirect effect is significant and relevant $\left(\beta_{2}=0.556, \mathrm{t}=4.709, \mathrm{p}<0.01\right.$ and $\left.\beta_{3}=0.443, \mathrm{t}=3.643, \mathrm{p}<0.01\right)$. 
(4) There is a significant relationship between organizational learning capability and organizational performance $\left(\beta_{3}=0.443, \mathrm{t}=3.643, \mathrm{p}<0.01\right)$.

Estimated indirect effect of altruistic leader behavior on performance is 0.246 . The $95 \%$ bias corrected confidence intervals for the indirect effect are between 0.136 and 0.386 , with a p-value of 0.001 for two-tailed significance test. Hence, the standardized indirect effect of altruistic leader behavior on performance is significantly different from zero at the 0.001 level and we can reject the null hypothesis of no mediation effect.

These four points, together with bootstrap analysis, provide evidence to support our hypotheses, as reported in figure 4 . This figure shows that the relationship between altruistic leader behavior and organizational performance is mediated by organizational learning capability, supporting hypothesis 1 . In other words, the relationship between altruistic leader behavior and organizational performance occurs through organizational learning capability. We also find a moderate and significant relationship between altruistic leader behaviors and organizational learning capability (hypothesis 2) and, finally, the relationship between organizational learning capability and organizational performance is also positive (hypothesis $3)$.

In summary, the significant and positive impact of altruistic leader behaviors on organizational performance evidenced in the direct effect model $(\alpha=0.215, \mathrm{t}=3.079, \mathrm{p}$ $<0.01)$ is due to a concept that had not been taken into account in this direct effect model: organizational learning capability. Particular attention should therefore be paid to organizational learning capability variables, so that actions associated with altruistic leader behaviors will translate into organizational performance. The results also reveal that organizational learning capability only partially depends on altruistic leader behaviors. Consequently, other factors, such as the presence of an organic organizational structure, must be affecting organizational learning capability practices. Other variables obviously exist that have not been considered in this study. 


\section{Conclusions}

The study of organizational learning capability has grown in importance over recent years. However, one of the key issues for organizations has received little research attention, namely, how to generate environments that have a high capacity for organizational learning. Pérez López et al. (2005, p. 239) suggest it would be useful to study the influence that variables such as organizational structure or leadership have on organizational learning. Although in recent years some studies have linked leadership with organizational learning (e.g., García Morales et al., 2006), few research has addressed the concept of altruistic leader behaviors (e.g., Sosik et al., 2009), which has received scant mention in the literature (e.g., Singh and Krishnan, 2008) despite its importance in a number of leadership styles, such as transformational or servant leadership, and its relevance today as an alternative to the egotistic leader.

The results confirm the model and the research hypotheses. The findings have important implications for the organizational learning literature and the leadership literature.

First, this study offers empirical evidence that organizational learning capability increases organizational performance, confirming hypothesis 3. Although there was some previous empirical evidence (Jerez-Gómez et al., 2005) for a direct and positive relationship between organizational learning capability and organizational performance, no previous work using Chiva et al.'s (2007) instrument had related it directly with performance. This study confirms that organizational learning capability, measured by Chiva et al.'s scale, positively and directly affects organizational performance, although it is clear that organizational performance is influenced by many other factors such as industry or the economic situation.

Second, altruistic leader behavior is positively related to organizational learning capability, confirming hypothesis 2 . Leaders with a selfless concern for the welfare of others promote environments in which to experiment, discuss, take risks, interact with the external 
environment and participate. In all likelihood, altruism provides the confidence to take up the individual and collective challenges that learning requires.

Third and finally, altruistic leader behavior has a positive and indirect effect on organizational performance, mediated by organizational learning capability, confirming hypothesis 1 . Hence, organizational learning capability also plays a key role in explaining how altruistic leader behavior affects organizational performance, essentially because it facilitates the creation of a creative, participatory and dialogue-based environment that promotes organizational learning.

Our research contributes to the organizational learning literature by analyzing and demonstrating the essential role of altruistic leader behavior as an antecedent of organizational learning capability. Pérez-López et al. (2005, p. 239) suggested studying the influence that variables such as leadership have on organizational learning; the present study focuses on one type of leadership that we considered could theoretically be a facilitator of organizational learning capability, namely, altruistic leader behavior.

We also believe that this research contributes to the leadership literature, specifically to the stream that seeks to relate leadership with organizational learning (e.g., Lloréns-Montes et al., 2005), by demonstrating empirically the positive relationship between altruistic leader behaviors and organizational learning capability. In addition, this study considers that although some studies had mentioned the concept of altruism in leadership (e.g., Singh and Krishnan, 2008), few research conceptualized it as such (Sosik et al., 2009). Given the growing importance for organizations of concepts such as Wilber's (2000) levels of consciousness or Maslow's (1971) levels of self-actualization and transcendence (Pandey and Gupta, 2008), which advocate abandoning or transcending egocentric approaches and raising awareness through compassion or altruism, we understand that altruistic leader behavior supports or sustains these ideas. Altruistic leader behavior can be regarded as the catalyst for 
creating organizations with a higher level of awareness, which may be associated with environments where creativity, learning and humanism are key players.

Moreover, leadership research and theory have been criticized as being too segmented, and calls have been made for more integration of findings from different leadership approaches (i.e., integrating leader traits, leader behaviors, follower cognitions, situational/contextual factors [see Yukl, 2010: 491]). We have had these calls in mind, as our theory touches on leader behaviors, contextual factors and organizational outcomes.

In addition, these academic contributions contain contributions of a business or applied nature. Organizations should be aware that hiring or fomenting altruistic leaders promotes organizational learning capability, which in turn improves their organizational performance. While it is true that this idea is not easily promoted, since it is a challenging and unusual concept in the business and organizational world, this study demonstrates the importance of implementing ways of organizing and leading that generate environments where learning can take place. Rosen and Sims (2011) examined whether altruistic behavior is habit forming. They found that engaging in charitable behavior (donations of money and time) when young is a strong predictor of adult altruistic behavior. Moss and Barbuto (2010) describe altruism as a component of character within an individual. Crossan et al. (2013) describe an approach to develop leadership character at the individual, group, and organizational level. They provide concrete suggestions on how to integrate a focus on character development into existing business programs. Burke (2006) studied why leaders fail, focusing on what he calls "darkside characteristics". One of the characteristics or behaviors mentioned is that leaders places self-interest first. Hogan and Curphy (1994) believe that darkside characteristics can be changed but this requires more intensive development than currently found in most leader training programs and cite evidence from a coaching program, based on work with 370 managers over a five year period, which showed that most managers were able to change a number of targeted behaviors. 
On the other hand, recruiting and fomenting altruistic leaders is not sufficient on its own to improve performance, and should be accompanied by implementing other facilitating factors of organizational learning such as dialogue or experimentation.

Apart from the verification of the research hypotheses, we have also conducted an additional analysis to test whether altruism is more highly related to some aspects of performance and not others. In this sense, we have repeated the study using as dependent variables each of the performance measures taken from the construct proposed by Tippins and Sohi (2003): customer retention, sales growth, profitability and return on investment. The results of this analysis show that the construct of altruistic leader behavior has no significant direct impact on the variable sales growth. However, the results for the other variables (customer retention, profitability and return on investment) allow us to report the overall mediating role of organizational learning capability. Given this situation, we checked that when the model includes the full dimension of organizational performance, as we define it, all the variables that make it up are significant $(\mathrm{t} \geq 1.96)$. In light of these results, we can conclude that the effect of altruistic leader behavior has a greater impact on some performance variables (customer retention, profitability and return on investment) than on others (sales growth), through organizational learning capability.

Moreover, altruistic behaviors are interpreted by their recipient as a sign that the person who acts in this way is trustworthy (Ferrin et al., 2006). Thus altruism generates a positive expectation about the behavior or intentions of the other party which could foster the development of trust between parties. Altruism may therefore foster trust within the organization. Given that altruistic behavior is present in different contemporary leadership styles, we believe that it could contribute to rebuilding trust in leaders.

Despite the results, our research has certain limitations that should be noted. As it is a transversal study, the relationships we tested reflect a snapshot in time. Although it is likely that conditions in which data were collected will remain at least for some time, this can not be 
guaranteed. Moreover, all the variables studied may have further effects on organizational performance in the future or the long term, aspects that are not dealt with here, since our study is not longitudinal. Apart from that, mediation is inherently a process that unfolds over time (MacKinnon et al., 2012). Therefore, future longitudinal studies might assess the longterm effects of altruistic leader behavior and organizational learning capability on organizational performance.

Our use of subjective performance assessment measures may be considered as another limitation in the measurement (Venkatraman, 1989). This option was chosen because of the difficulties of obtaining objective data, which can also be distorted by accounting methods (Dechow et al., 1995). However, future research might attempt to overcome these shortcomings by using objective data.

Because this research was carried out in a particular population of organizations, our results are obviously limited to this type of organization. The present study uses a sample of firms with an excellent human resource management record; our analysis was therefore of a heterogeneous sample in terms of size and industry, an aspect that could affect firms' organizational performance. Future research might consider conducting this study in firms from a single sector and of a similar size. It would also be interesting to perform this analysis on samples similar to the ones used here, but in other European countries, in order to compare situations.

Further, our model does not consider the sources or antecedents of altruistic attitudes in leaders; future studies should therefore explore what personal or contextual features promote altruism in order to extend knowledge on the measures that can be taken to select or strengthen this attitude in organizational contexts.

We also believe that the results of this research could be improved by exploring the hows and whys through qualitative research or case studies in some of the outstanding firms 
from the sample. They might also introduce new explanatory variables that appear to be pivotal, such as trust or conflict.

In any event, we understand that this research is only an initial step in studying the relationship of altruistic leaders to organizational learning capability. 


\section{References}

Alegre, J., and Chiva, R. (2013). Linking Entrepreneurial Orientation and Firm Performance: The Role of Organizational Learning Capability and Innovation Performance. Journal of Small Business Management. DOI: 10.1111/jsbm.12005

Anderson, J. C., and Gerbing, D. W. (1988). Structural equation modeling in practice: a review and recommended two-step approach. Psychological Bulletin, 103(3), 411-423.

Avolio, B. J. (2007). Promoting more integrative strategies for leadership theory building. American Psychologist, 62, 25-33.

Avolio, B. J., and Gardner, W. L. (2005). Authentic leadership development: Getting to the root of positive forms of leadership. The Leadership Quarterly, 16, 315-338.

Bagozzi, R. P., Youjae, Y., and Phillips, L. W. (1991). Assessing Construct Validity in Organizational Research. Administrative Science Quarterly, 36(3), 421-458.

Barbuto, J. E., Jr., and Wheeler, D. W. (2006). Scale development and construct clarification of servant leadership. Group and Organization Management, 31(3), 300-326.

Batson, C., Ahmad, N., and Stocks, E. L. (2011). Four forms of prosaically motivation: Egoism, altruism, collectivism, and principlism. In D. Dunning \& D. Dunning (Eds.), Social Motivation (pp. 103-126). New York, NY: Psychology Press.

Berson, Y., Nemanich, L. A., Waldman, D. A., Galvin, B. M., and Keller, R. T. (2006). Leadership and organizational learning: A multiple levels perspective. The Leadership Quarterly, 17, 577-594. 
Bolino, M. C., Turnley, W. H., and Niehoff, B. P. (2004). The other side of the story: Reexamining prevailing assumptions about organizational citizenship behavior. Human Resource Management Review, 14, 229-246.

Brown, M. E., and Treviño, L. K. (2006). Ethical leadership: A review and future directions. The Leadership Quarterly, 17, 595-616.

Burke, R. J. (2006). Why leaders fail: exploring the darkside. International Journal Of Manpower, 27(1), 91-100.

Cameron, K. S., Bright, D., and Caza, A. (2004). Exploring the relationships between organizational virtuousness and performance. American Behavioral Scientist, 47, 766-790.

Capon, N., Farley, J.U., and Hoenig, S.M. (1990). A Meta-Analysis of Financial Performance. Management Science, 36(10), 1143-59.

Chang, C. C., Tsai, M. C., and Tsai, M. S. (2011). The organizational citizenship behaviors and organizational commitments of organizational members influences the effects of organizational learning. International Journal of Trade, Economics and Finance, 2(1), 61-66.

Chiva, R., and Alegre, J. (2009). Organizational learning capability and job satisfaction: An empirical assessment in the ceramic tile industry. British Journal of Management, 20(3), 323-340.

Chiva, R., Alegre, J., and Lapiedra, R. (2007). Measuring organisational learning capability among the workforce. International Journal of Manpower, 28(3/4), 224-242. 
Christmann, P. (2000). Effects of "best practices" of environmental management on cost advantage: The role of complementary assets. Academy of Management Journal, 43(4), 663-680.

Cotton, J. L., Vollrath, D. A., Foggat, K. L., Lengnick-Hall, M. L., and Jennings, K. R. (1988). Employee participation: diverse forms and different outcomes, Academy of Management Review, 13(1), 8-22.

Crossan, M., Mazutis, D., Seijts, G., and Gandz, J. (2013). Developing Leadership Character in Business Programs. Academy Of Management Learning \& Education, 12(2), 285-305.

Daily, C.M., and Dollinger, M.J. (1992). An empirical examination of ownership structure in family and professionally managed firms. Family Business Review, 5 (2), 117136.

Dechow, P. M., Sloan, R. G., and Sweeney, A. (1995). Detecting earnings management. Accounting Review, 70(2), 193-225.

Dinh, J. E., Lord, R. G., Gardner, W. L., Meuser, J. D., Liden, R. C., and Hu, J. (2014). Leadership theory and research in the new millennium: Current theoretical trends and changing perspectives. Leadership Quarterly, 25(1), 36-62.

Edmonson, A. (1999). Psychological safety and learning behavior in work teams. Administrative Science Quarterly, 42(2), 350-383.

Fassina, N. E., Jones, D. A., and Uggerslev, K. L. (2008): Meta - analytic tests of relationships between organizational justice and citizenship behavior: testing agent - system and shared-variance models. Journal of Organizational Behavior, 29(6), 805-828. 
Ferrin, D. L., Dirks, K. T., and Shah, P. P. (2006). Direct and Indirect Effects of Third-Party Relationships on Interpersonal Trust. Journal Of Applied Psychology, 91(4), 870-883.

Fornell, C., and Larcker, D. F. (1981). Evaluating structural equation models with unobservable variables and measurement error. Journal of Marketing Research, 18(1), 39-50.

Fry, L. (2003). Toward a theory of spiritual leadership. The Leadership Quarterly, 14, 693727.

Fry, L. W., Vitucci, S., and Cedillo, M. (2005). Spiritual leadership and army transformation: theory, measurement, and establishing a baseline. The Leadership Quarterly, $16,835-62$.

García-Morales, V. J., Jiménez-Barrionuevo, M. M., and Gutiérrez-Gutiérrez, L. (2011). Transformational leadership influence on organizational performance through organizational learning and innovation. Journal of Business Research.

García Morales, V. J., Llorens Montes, F. J., and Verdú Jover, A. J. (2006). Antecedents and Consequences of Organizational Innovation and Organizational Learning in Entrepreneurship. Industrial Management and Data Systems, 106(1), 21-42.

García Morales, V. J., Matías Reche, F., and Hurtado Torres, N. (2008). Influence of Transformational Leadership on Organizational Innovation and Performance Depending of the Level of Organizational Learning and Communication: An Empirical Examination of the Pharmaceutical Sector. Journal of Organizational Change Management, 21 (2), 188-212. 
Gardner, W. L., Avolio, B. J., Luthans, F., May, D. R., and Walumba, F. O. (2005). Can you see the real me? A self-based model of authentic leader and follower development. The Leadership Quarterly, 373-394.

Gatignon, H., Tushman, M. L., Smith, W., and Anderson, P. (2002). A Structural Approach to Assessing Innovation: Construct Development of Innovation Locus, Type, and Characteristics. Management Science, 48(9), 1103-1122.

Gersick, K.E., Davis, J.A., Hampton, M.M., and Lansberg, I. (1997): Generation to Generation: Life Cycles of the Family Business. Harvard Business School Press, Cambridge, MA.

Gibson, C. B., and Birkinshaw, J. (2004). The antecedents, consequences, and mediating role of organizational ambidexterity. Academy of Management Journal, 47(2), 209226.

Goh, S. C., Elliot, C., and Quon, T. K. (2012). The relationship between learning capability and organizational performance. A meta-analytic examination. The Learning Organization, 19(2), 92-108.

Greenleaf, R. K. (1977). Servant Leadership. Mahwah, NJ: Paulist Press.

Hogan, R., and Curphy, G. J. (1994). What we know about leadership?. American Psychologist, 49(6), 493. House, R. J., \& Aditya, R. N. (1997). The Social Scientific Study of Leadership: Quo Vadis?. Journal Of Management, 23(3), 409.

House, R. J., Hanges, P. J., Ruiz-Quintanilla, S. A., Dorfman, P.W., Javidan, M., Dickson, and M., and Gupta, V. (1999). Cultural influences on leadership and 
organizations. Project Globe. Advances in global leadership, vol. 1: 171-233, Stanford, CT: JAI Press.

Isaacs, W. (1993). Dialogue, collective thinking, and organizational learning, Organizational Dynamics, 22(2), 24-39.

Jerez-Gómez, P., Céspedes-Lorente, J., and Valle-Cabrera, R. (2005). Organizational learning and compensation strategies: evidence from the Spanish chemical industry. Human Resource Management, 44(3), 279-299.

Kanungo, R.N., and Conger, J.A. (1993). Promoting altruism as a corporate goal. Academy of Management Executive, 7(3), 37- 48.

Kanungo, R.N., and Mendonca, M. (1996), Ethical Dimensions of Leadership, Sage Publications, Thousand Oaks, CA.

Khandekar, A., and Sharma, A. (2006). Organizational learning and performance: understanding Indian scenario in present day context, Education + Training, 48(8/9), 682-692.

Lloréns Montes, F. J., Ruiz Moreno, A., and García Morales, V. J. (2005). Influence of Support Leadership and Teamwork Cohesion on Organizational Learning, Innovation and Performance: An Empirical Examination. Technovation, 25(10), 1159-1172.

MacKinnon, D. P., Coxe, S., and Baraldi, A. N. (2012). Guideliness for the Investigation of Mediating Variables in Business Research. Journal of Business and Psychology, 27, 1-14.

Maslow, A. (1971). The farther reaches of human nature. New York: Viking. 
Moss, J. A., and Barbuto Jr., J. E. (2010). Testing the Relationship Between Interpersonal Political Skills, Altruism, Leadership Success and Effectiveness: A Multilevel Model. Journal Of Behavioral \& Applied Management, 11(2), 155-174.

Nevis, E., DiBella, A.J., and Gould, J.M. (1995). Understanding organization learning systems. Sloan Management Review, 36(2), 73-85.

Nunnally, J. C. 1978. Psychometric Theory. New York: McGraw-Hill.

Organ, D. (1988). Organizational citizenship behavior: The good soldier syndrome. Lexington, MA: Lexington Books.

Organ, D. W., Podsakoff, P. M., and MacKenzie, S. B. (2006). Organizational citizenship behavior: Its nature, antecedents, and consequences. Thousand Oaks, CA: Sage.

Ozcelik, H., Langton, N., and Aldrich, H. (2008). Doing well and doing good. The relationship between leadership practices that facilitate a positive emotional climate and organizational performance. Journal of Managerial Psychology, 23(2), 186-203.

Owens, B. P., and Hekman, D. R. (2012). Modeling how to grow: an inductive examination of humble leader behaviors, contingencies and outcomes. Academy of Management Journal, 55(4), 787-818.

Pandey, A., and Gupta, R.K. (2008). A Perspective of Collective Consciousness of Business Organizations. Journal of Business Ethics, 80 (4). 
Pérez López, S., Montes Peron, M. J., and Vázquez Ordás, J. C. (2005). Human resource practices, organizational learning and business performance. Human Resource Development International, 8(2), 147-164.

Podsakoff, P. M., and Organ, D. W. (1986). Self reports in organizational research: problems and prospects, Journal of Management, 12(2), 531-544.

Podsakoff, P. M., and MacKenzie, S. B. (1997). Impact of Organizational Citizenship Behavior on Organizational Performance: A Review and Suggestion for Future Research. Human Performance, 10(2), 133.

Popper, M. and Lipshitz, R. (1993). Putting leadership theory to work: a conceptual framework for theory-based leadership development. Leadership and Organization Development Journal, 14(7), 23-27.

Porter, L. W., and McLaughlin, G. B. (2006). Leadership and the organizational context: Like the weather? The Leadership Quarterly, 17(6), 559-576.

Preacher, K. J., and Hayes, A. F. (2008). Asymptotic and resampling strategies for assessing and comparing indirect effects in multiple medatior models. Behavior Research Methods, 40(3), 879-891.

Prieto, I., and Revilla, E. (2006). Assessing the Impact of Learning Capability on Business Performance: Empirical Evidence from Spain. Management Learning, 37(4), 499-522.

Rosen, H. S., and Sims, S. T. (2011). Altruistic behavior and habit formation. Nonprofit Management \& Leadership, 21(3), 235-253.

Rowe, W.G. (2001). Creating wealth in organizations: The role of strategic leadership. Academy of Management Executive, 15, 81-94. 
Simmons, R. G. (1991). Altruism and Sociology. Sociological Quarterly, 32, 1-22.

Singh, N., and Krishnan, V. R. (2008). Self-sacrifice and transformational leadership: mediating role of altruism. Leadership and Organization Development Journal, 29(3): 261-274.

Smith, C. A., Organ, D. W., and Near, J. P. (1983). Organizational Citizenship Behavior: Its Nature and Antecedents. Journal of Applied Psychology, 68(4), 653-663.

Sendjaya, S., Sarros, J. C., and Santora, J. C. (2008). Defining and Measuring Servant Leadership Behaviour in Organizations. Journal Of Management Studies, $45(2), 402-424$.

Sosik, J. J., Jung, D., and Dinger, S. L. (2009). Values in Authentic Action: Examining the Roots and Rewards of Altruistic Leadership. Group and Organization Management, 34(4), 395-431.

Spicer, D., and Sadler-Smith, E. (2006). Organizational learning in smaller manufacturing firms, International Small Business Journal, 24(2), 133-158.

Steyrer, J., Schiffinger, M., and Lang, R. (2008). Organizational commitment - A missing link between leadership behavior and organizational performance? Scandinavian Journal of Management, 24, 364-374.

Tierney, P., Farmer, S. M., and Graen, C. B. (1999). An examination of leadership and employee creativity: The relevance of traits and rejationships. Personnel Psychology, 52, 591-620.

Tippins, M. J., and Sohi, R. S. (2003). It competency and firm performance: Is organizational learning a missing link? Strategic Management Journal, 24(8), 745-761. 
Tyler, T.R., and Lind E.A. (1992). A relational model of authority in groups. In M. Zanna (Ed.). Advances in experimental social psychology (Vol. 25, pp. 115-191). New York: Academic Press.

Venkatraman, N. (1989). Strategic orientation of business enterprises: The construct, dimensionality, and measurement. Management Science, 35(8), 942-962.

Valerie I., S., Manuel, L., Christopher, P., Beyza, G., and Juhi, P. (2011). Adaptive, generative, and transformative learning in project teams. Team Performance Management, 17(3/4), 146-167.

Vera, D., and Crossan, M. (2004). Strategic leadership and organizational learning. Academy of Management Review, 29(2), 222-240.

Wilber, K. (2000). A theory of everything: an integral vision for business, politics, science and spirituality. Shambala Publications: Massachusetts.

Xenikou, A., and Simosi, M. (2006). Organizational Culture and Transformational Leadership as predictors of business unit performance. Journal of Managerial Psychology, 21(6), 566-579.

Yen, H. R., and Niehoff, B. P. (2004): Organizational citizenship behaviors and organizational effectiveness: Examining relationships in Taiwanese Banks. Journal of Applied Social Psychology, 34(8), 1617-1637.

Yukl, G. (2010). Leadership in organizations. 7th International edition. London: Prentice Hall.

Yukl, G. (2012). Effective Leadership Behavior: What We Know and What Questions Need More Attention. Academy of Management Perspectives, November, 66-85. 
Zhu, W., Chew, I., and Spangler, W., (2005). CEO transformational leadership and organizational outcomes: The mediating role of human-capital-enhancing human resource management. The Leadership Quarterly, 16(1), 39-52. 


\section{APPENDIX A: QUESTIONNAIRE}

About altruistic leadership: Barbuto and Wheeler (2006).

\begin{tabular}{|l|c|}
\hline ALT1. The leaders of this organization put the interests of the people above their own & $1-2-3-4-5$ \\
\hline ALT2. The leaders of this organization do all they can to help people & $1-2-3-4-5$ \\
\hline $\begin{array}{l}\text { ALT3. The leaders of this organization sacrifice their own interests to meet the needs of } \\
\text { others }\end{array}$ & $1-2-3-4-5$ \\
\hline ALT4. 4. The leaders of this organization go beyond the call of duty to help others & $1-2-3-4-5$ \\
\hline
\end{tabular}

Organizational learning capability: Chiva, Alegre and Lapiedra (2007).

\section{About experimentation:}

\begin{tabular}{|l|c|}
\hline EXP1. People here receive support and encouragement when presenting new ideas. & $1-2-3-4-5$ \\
\hline $\begin{array}{l}\text { EXP 2. Initiative often receives a favorable response here, so people feel encouraged to } \\
\text { generate new ideas. }\end{array}$ & $1-2-3-4-5$ \\
\hline
\end{tabular}

About risk taking:

\begin{tabular}{|l|c|}
\hline R1. People are encouraged to take risks in this organization. & $1-2-3-4-5$ \\
\hline R2. People here often venture into unknown territory. & $1-2-3-4-5$ \\
\hline
\end{tabular}

\section{About interaction with the external environment:}

\begin{tabular}{|l|c|}
\hline $\begin{array}{l}\text { ENV1. It is part of the work of all staff to collect, bring back, and report information } \\
\text { about what is going on outside the company }\end{array}$ & $1-2-3-4-5$ \\
\hline $\begin{array}{l}\text { ENV2. There are systems and procedures for receiving, collating and sharing information } \\
\text { from outside the company. }\end{array}$ & $1-2-3-4-5$ \\
\hline ENV3. People are encouraged to interact with the environment. & $1-2-3-4-5$ \\
\hline
\end{tabular}

\section{About dialogue:}

\begin{tabular}{|l|c|}
\hline DIA1. Employees are encouraged to communicate. & $1-2-3-4-5$ \\
\hline DIA2. There is a free and open communication within my work group. & $1-2-3-4-5$ \\
\hline DIA3. Managers facilitate communication. & $1-2-3-4-5$ \\
\hline DIA4. Cross-functional teamwork is a common practice here. & $1-2-3-4-5$ \\
\hline
\end{tabular}

\section{About participative decision making:}

\begin{tabular}{|l|c|}
\hline $\begin{array}{l}\text { DEC1. Managers in this organization frequently involve employees in important } \\
\text { decisions. }\end{array}$ & $1-2-3-4-5$ \\
\hline DEC2. Policies are significantly influenced by the view of employees. & $1-2-3-4-5$ \\
\hline DEC3. People feel involved in main company decisions. & $1-2-3-4-5$ \\
\hline
\end{tabular}

About organizational performance: Tippins and Sohi (2003). Perceptions about firm or organization results as compared to its competitors.

\begin{tabular}{|l|c|}
\hline PER1. Customer retention & $1-2-3-4-5$ \\
\hline PER2. Sales growth & $1-2-3-4-5$ \\
\hline PER3. Profitability & $1-2-3-4-5$ \\
\hline PER4. Return on investment & $1-2-3-4-5$ \\
\hline
\end{tabular}


Table 1

Factor correlations, means, standard deviations and Cronbach's alpha

\begin{tabular}{lccccccccc}
\hline & $\underline{\text { Mean }}$ & $\underline{\text { s.d. }}$ & $\underline{\underline{\text { ALT }}}$ & $\underline{\text { PER }}$ & $\underline{\text { EXP }}$ & $\underline{\text { RISK }}$ & $\underline{\text { ENT }}$ & $\underline{\text { DIA }}$ & $\underline{\text { DEC }}$ \\
PER & 3.43 & 0.67 & $(0.89)$ & & & & & & \\
EXP & 3.57 & 0.58 & 0.190 & $(0.82)$ & & & & & \\
RISK & 3.99 & 0.56 & 0.357 & 0.254 & $(0.80)$ & & & & \\
ENT & 3.37 & 0.85 & 0.189 & $0.147^{*}$ & 0.312 & $(0.84)$ & & & \\
& 3.69 & 0.67 & 0.131 & 0.271 & 0.175 & 0.273 & $(0.83)$ & & \\
DIA & & & & & & \\
DEC & 3.13 & 0.55 & 0.381 & 0.264 & 0.404 & 0.282 & 0.345 & $(0.84)$ & \\
& 3.47 & 0.68 & 0.371 & 0.290 & 0.331 & 0.315 & 0.360 & 0.495 & $(0.87)$
\end{tabular}

Notes: For the standard deviations and factor correlations, we used the mean of the items making up each dimension. Cronbach's alpha coefficients are given in parenthesis.

* Significant correlation $(\mathrm{p}<0.05)$. Other correlations not marked with an asterisk present a significant correlation at $\mathrm{p}<0.01$.

\section{Table 2}

Reliability of the measurement scales

\begin{tabular}{|c|c|c|}
\hline Construct & $\frac{\text { Composite }}{\text { reliability }}$ & $\frac{\text { Average }}{\text { variance }} \frac{\text { extracted }}{}$ \\
\hline Leader altruism (4 items) & 0.901 & 0.696 \\
\hline Organizational performance (4 items) & 0.829 & 0.555 \\
\hline Experimentation $(2 \text { items })^{(*)}$ & 0.811 & 0.684 \\
\hline Risk acceptance $(2 \text { items })^{(*)}$ & 0.845 & 0.732 \\
\hline Interaction with external environment ( 3 items) & 0.836 & 0.631 \\
\hline Dialogue (4 items) & 0.851 & 0.589 \\
\hline Participative decision making ( 3 items) & 0.881 & 0.713 \\
\hline
\end{tabular}

(*) The Cronbach's alpha coefficient for the experimentation and risk acceptance dimensions, both with two items, was performed using SPSS 17.0 software; EQS 6.1 software was used for the other dimensions. Following Chiva and Alegre (2009), factor loadings obtained from the second-order organizational learning capability factor model were used to calculate the composite reliability and average variance extracted for these two dimensions.

\section{Table 3}

Structural equations to test the hypothesis that organizational learning capability mediates in the relationship between altruistic leadership and organizational performance.

\begin{tabular}{|c|c|}
\hline Structural equation & $\mathbf{R}^{2}$ \\
\hline \multicolumn{2}{|l|}{ Direct effect model } \\
\hline $\begin{array}{c}\text { PER }=0.215 * \text { ALT }+0.024 * \text { SIZE }+0.162 * \text { SECTOR } \\
(\mathrm{t}=3.079) \quad(\mathrm{t}=0.329) \quad(\mathrm{t}=2.419)\end{array}$ & 0.073 \\
\hline \multicolumn{2}{|l|}{ Mediation effect model } \\
\hline $\begin{array}{c}\text { PER }=-0.027 * \text { ALT }+0.443 * \text { OLC }+0.042 * \text { SIZE }+0.154 * \text { SECTOR } \\
\quad(\mathrm{t}=-0.318) \quad(\mathrm{t}=3.643) \quad(\mathrm{t}=0.605) \quad(\mathrm{t}=2.432)\end{array}$ & 0.209 \\
\hline $\begin{array}{c}\text { OLC }=0.556 * A L T \\
(t=4.709)\end{array}$ & 0.309 \\
\hline
\end{tabular}




\section{Figures}

\section{Figure 1}

\section{Conceptual model}
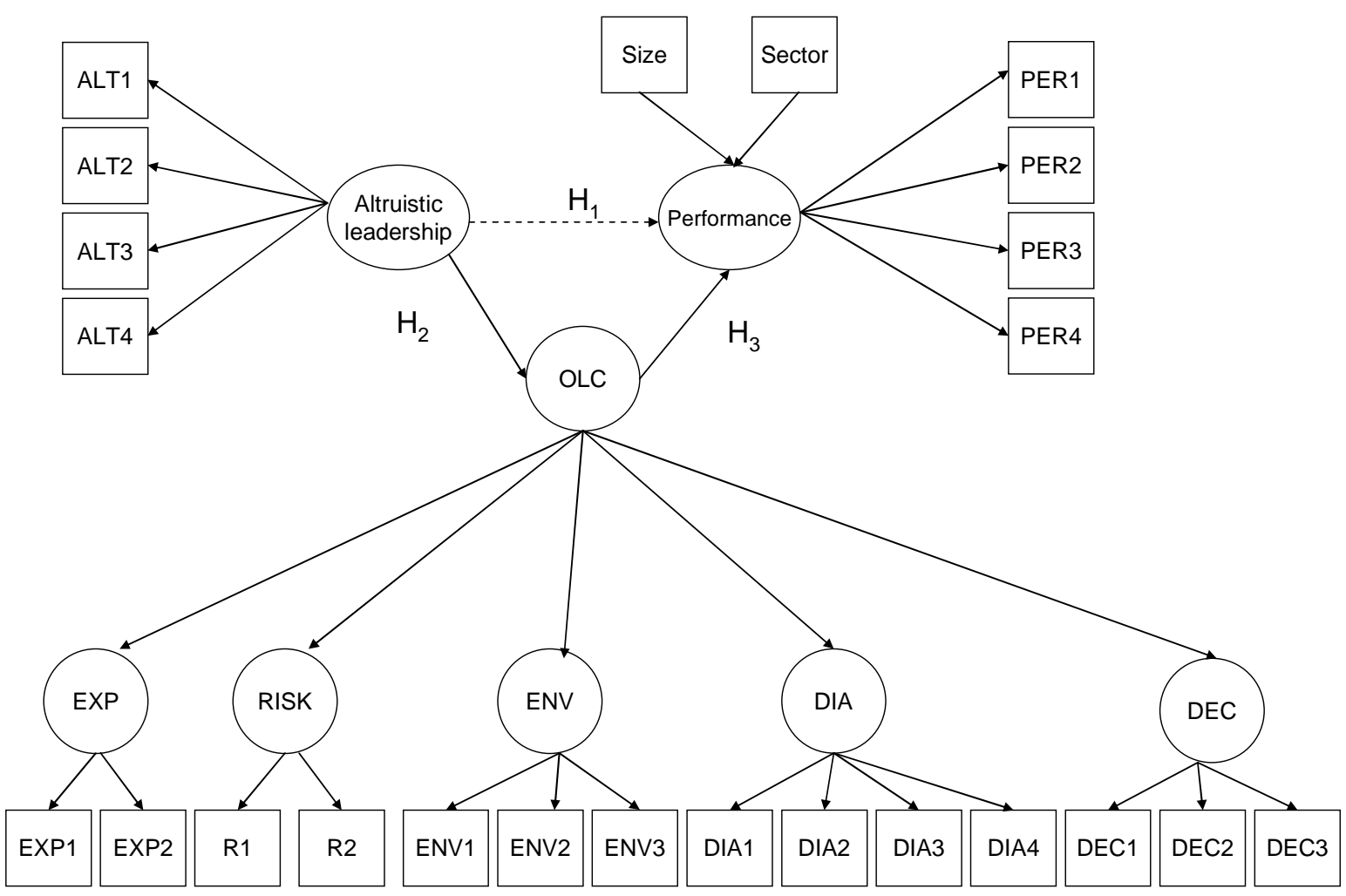

\section{Figure 2}

Confirmatory Factor Analyses for Organizational Learning Capability (OLC)

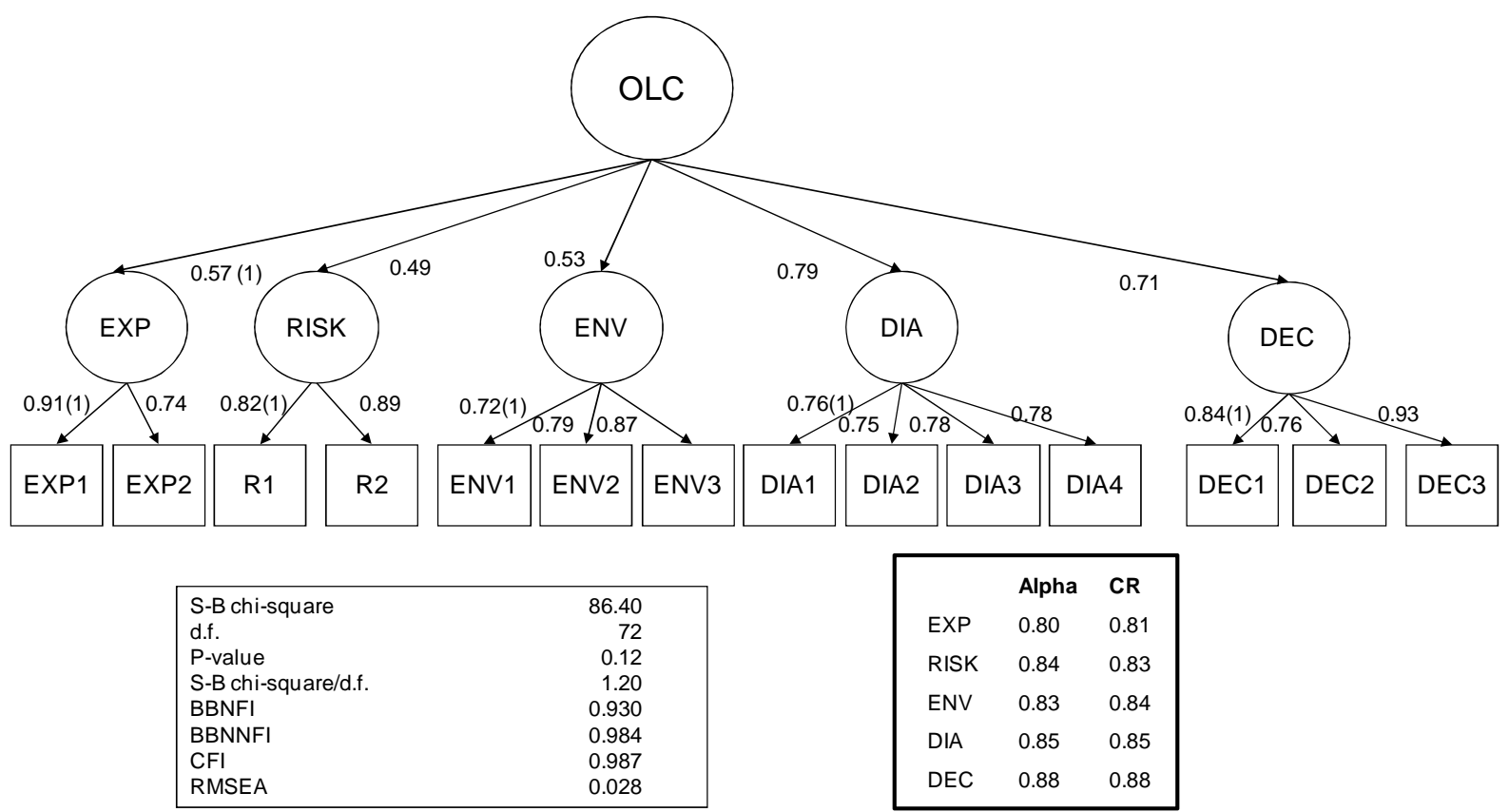

(1) The parameter was equaled to 1 to fix the latent variable scale. Parameter estimates are standardized. All parameter estimates are significant at a 95\% confidence level. 


\section{Figure 3}

Direct effect model: Altruistic leadership and organizational performance.

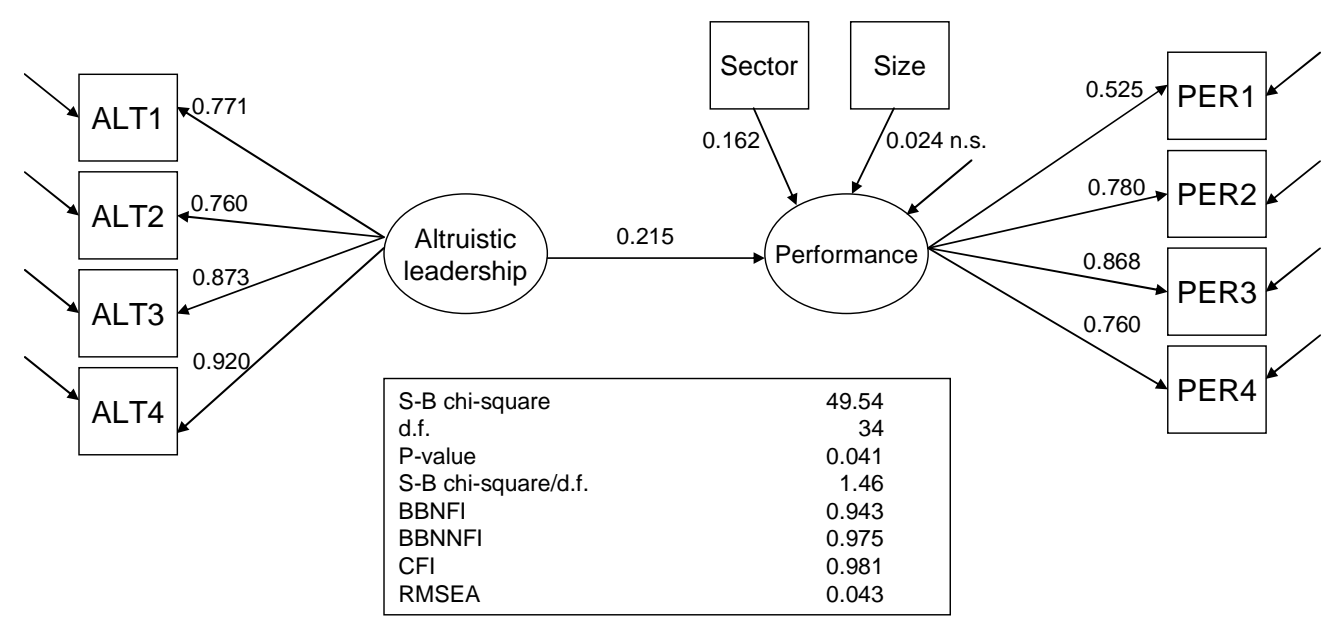

\section{Figure 4}

Mediating effect model: Altruistic leadership, organizational learning capability and organizational performance.

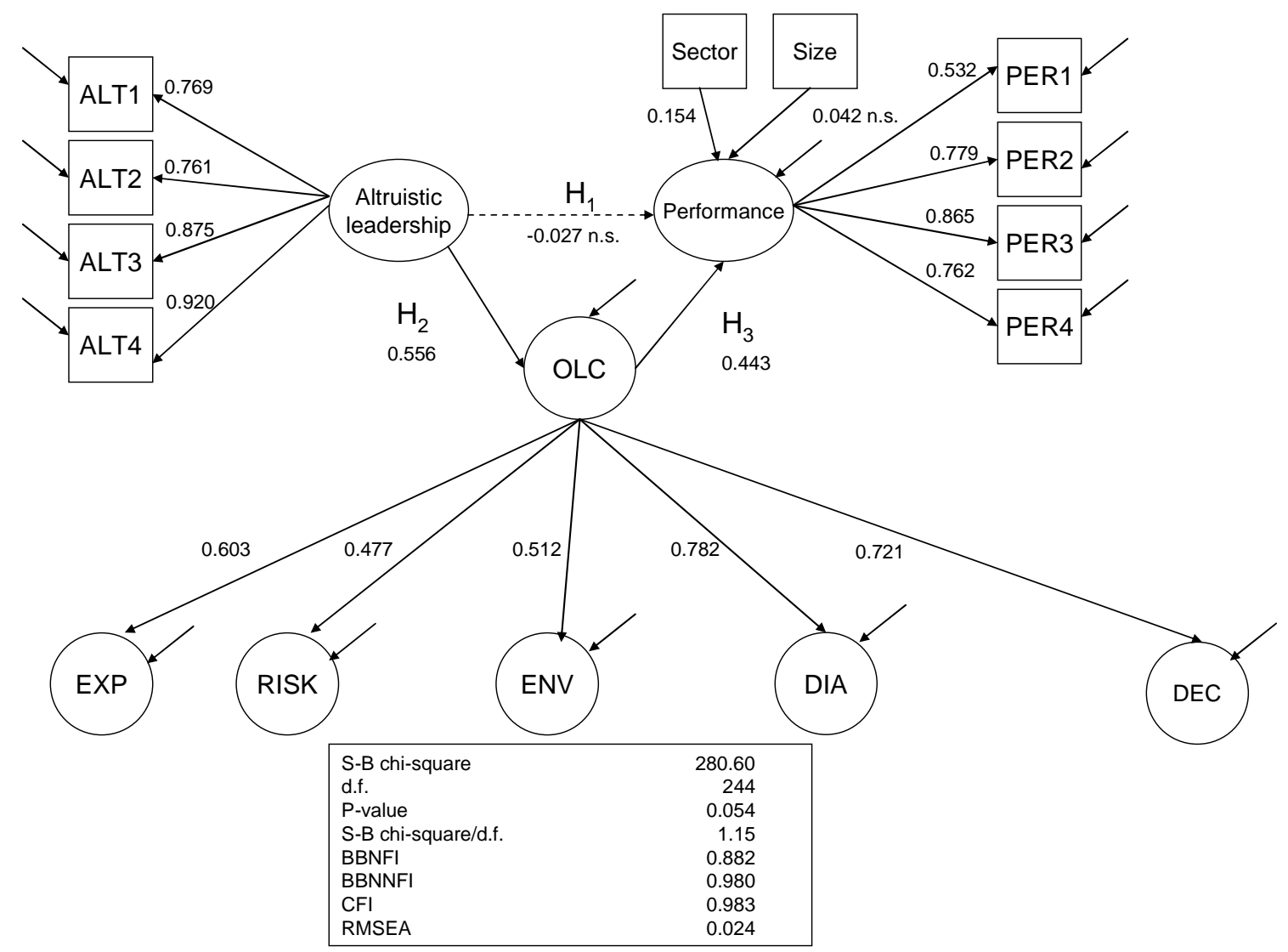

(a) Organizational learning capability (OLC) is a second-order factor. For the sake of brevity, only the first-order loadings are shown. The item loadings for these first-order factors are all significant at $p<0.001$. 